\title{
Letramento literário e digital: as bibliotecas digitais para crianças e o caso do Elefante Letrado
}

\section{RESUMO}

O objetivo deste artigo é apresentar o resultado de uma análise da plataforma de leitura de livros digitais Elefante Letrado (http://www.elefanteletrado.com.br/) à luz do campo de estudos dedicado aos letramentos, com ênfase nos conceitos de 'letramento digital' e 'letramento literário', tomando a plataforma brasileira Elefante Letrado como estudo de caso. As análises e reflexões aqui propostas procuram elucidar a perspectiva de letramento literário e digital com a qual a plataforma Elefante Letrado está alinhada. Os principais autores vinculados aos estudos sobre letramento utilizados para fundamentar as análises são Brian Street, Roxane Rojo, Rildo Cosson, Ângela Kleiman, Eduardo Moura, entre outros. Além disso, também são utilizados os trabalhos de pesquisadores sobre o livro literário digital e sobre bibliotecas digitais, tais como Procopio, Teale e Yokota, entre outros.

PALAVRAS-CHAVE: Bibliotecas digitais. Letramento literário. Letramento digital. Literatura infantojuvenil digital. 


\section{INTRODUÇÃO}

O objetivo deste artigo é apresentar o resultado de uma análise da plataforma de leitura de livros digitais Elefante Letrado (http://www.elefanteletrado.com.br/) à luz do campo de estudos dedicado aos letramentos, com ênfase nos conceitos de 'letramento digital' e 'letramento literário'. A motivação para realizar estas reflexões emerge dos interesses pessoais dos autores: um pesquisador da leitura em ambiente digital e uma pesquisadora de temas relacionados à leitura e à escrita, também mãe de um aluno que faz uso da biblioteca digital aqui analisada. O Elefante Letrado foi criado em 2014 para estudantes do ensino fundamental I (do 1 음 5 o ano). Atualmente, está presente em 10 estados brasileiros e em cinco norte-americanos, ofertando mais de 500 livros em português e 450 em inglês (http://www.elefanteletrado.com.br/). Ao acessar a plataforma, o aluno/leitor, após selecionar algum e-book do acervo, poderá optar por sua leitura ou pela audição automática, além de poder realizar as atividades complementares à leitura disponíveis naquele ambiente.

Com base no pressuposto teórico segundo o qual os letramentos promovidos na escola devem levar em conta as demais práticas de letramento existentes na sociedade, auxiliando o estudante a desenvolver "estratégias e capacidades adequadas aos diversos textos que circulam em outras instituições onde se concretizam as práticas sociais" (KLEIMAN, 2005, p. 56), as análises aqui propostas procuram elucidar a perspectiva de letramento literário e digital com a qual a plataforma Elefante Letrado está alinhada. Os principais autores vinculados aos estudos sobre letramento utilizados para fundamentar essa discussão são Brian Street, Roxane Rojo, Rildo Cosson, Angela Kleiman, Eduardo Moura, entre outros. Além disso, também são utilizados os trabalhos de pesquisadores sobre o livro literário digital e sobre bibliotecas digitais, tais como Procopio, Teale e Yokota, entre outros.

Os dados empíricos utilizados para a análise foram coletados a partir da navegação dos pesquisadores junto a um aluno de 50 ano de um colégio da rede de ensino privada de Porto Alegre/RS, que é filho de um dos autores deste artigo e que será doravante mencionado como "MR" neste artigo. O colégio é uma fundação administrada por uma diretoria e um conselho deliberante compostos por pais e mães de estudantes; portanto, trata-se de um colégio comunitário. Propõe um trabalho pedagógico progressista, humanitário e democrático, embasado na liberdade de pensamento. Atende a um público de classe média e média-alta da cidade. As famílias são, em sua maioria, profissionais liberais, funcionários públicos, professores universitários e vereadores. A plataforma está sendo utilizada, na escola, desde março de 2019 , tendo sido disponibilizada aos alunos das turmas de 1음 ao 5o ano do Ensino Fundamental mediante pagamento obrigatório de uma taxa acrescida à mensalidade escolar.

Os procedimentos metodológicos da pesquisa passaram pelas seguintes etapas: inicialmente, reconhecimento e navegação exploratória pela plataforma junto a "MR"; posteriormente, o acompanhamento da leitura de duas obras literárias que haviam sido designadas pela professora de MR: Wangari Mathaai: a mulher que plantou árvores, de Frank Prévot, e Ímpar, de Marcelo Carneiro Cunha; os pesquisadores também acompanharam a realização das tarefas das referidas obras por MR, as quais estão propostas na plataforma. Além disso, as análises e reflexões aqui apresentadas também se baseiam nas informações que se 
encontram no site e no blog da plataforma Elefante Letrado com vistas a "recolher" informações sobre a organização, seu modo de funcionamento, depoimentos sobre sua aplicação em outros espaços escolares etc. $O$ trabalho de acompanhamento da primeira obra foi realizado sem a captura de imagem, uma vez que não sabíamos que não era possível retomar a tarefa depois de terminada. Já no caso da segunda obra e do site, foi possível capturar e armazenar algumas imagens para análise.

Para dar conta dos objetivos aqui propostos, o artigo está dividido em cinco seções. Após esta breve introdução, há uma discussão sobre letramento digital e literário, seguida de uma seção dedicada ao e-book e às plataformas de leitura em ambiente digital. Por fim, apresentam-se os resultados das análises, seguidos de uma conclusão.

\section{LETRAMENTO DIGITAL E LITERÁRIO}

Segundo Ângela Kleiman (2005, p. 5), "letramento" é um conceito criado para referir-se aos usos da língua escrita não somente na escola, mas em todo lugar." Em termos bastante simplificados, o letramento pode ser definido como "uma abreviatura para práticas sociais de leitura e escrita" ou como "um tipo específico de prática comunicativa" na qual é utilizado algum material escrito (STREET, 2014, p. 18). Brian Street (2014), um dos fundadores desse campo de estudos, é um antropólogo interessado em colocar em evidência as mais variadas situações sociais e culturais em que a escrita e a leitura são utilizadas, principalmente aquelas que normalmente são desvalorizadas ou simplesmente desconsideradas em nossa sociedade. Alguns exemplos são a discussão sobre uma receita realizada por um grupo de mulheres que pretende fazer um bolo, os recados e poemas de amor que algum casal apaixonado, no sudeste asiático, inscreve sobre bambus ou em folhas de palmeira, a leitura e a discussão do Corão por parte de grupos rurais no Irã, entre inúmeros outros.

Diante desse contexto, enquanto educadores inseridos em instituições formais de ensino, urge perguntarmos 'o que essas discussões de caráter marcadamente socioantropológico têm a nos dizer e ensinar sobre o letramento escolar/escolarizado'. Primeiramente, essa perspectiva nos ensina que não há um letramento apenas, mas vários letramentos, mesmo na escola e nas demais instituições formais de ensino, como a universidade. Embora, nesses espaços, predominem os "letramentos dominantes" (ROJO, 2008, p. 582), caracterizados por tipos de textos/gêneros discursivos - como a dissertação, o ensaio, a monografia, a literatura canônica etc - e por práticas mais frequentes e mais valorizadas do que outras - como a leitura e a discussão de textos escritos; a realização de exercícios; a produção textual - a escola e a universidade também estão permeadas pelos “letramentos vernaculares' (ibidem), não tão valorizados, que os sujeitos trazem de seus próprios contextos: participação nas redes sociais da internet, trocas de mensagens pelo WhatsApp, participação em grupos de leitura e discussão de textos religiosos, fruição e produção de textos literários em ambientes virtuais e não-virtuais, fruição de textos musicais oriundos da cultura pop, leitura e discussão de best sellers e suas adaptações para TV e cinema, entre inúmeras outras práticas. 
A pesquisadora Roxane Rojo (2008, p. 584) afirma que o ensino escolarizado de práticas de leitura não deve ignorar ou apagar os letramentos das culturas locais de seus agentes (professores, alunos, comunidade escolar), mas colocá-los em contato com os letramentos valorizados e institucionais. Ângela Kleiman (2005, p. 26), por sua vez, ressalta que um outro aspecto a ser considerado é a valorização de práticas e estratégias mais colaborativas, típicas dos letramentos não-escolares, uma vez que os letramentos escolarizados geralmente valorizam práticas mais individualizadas. Além disso, Kleiman também afirma que os letramentos não escolarizados podem nos inspirar a realizar projetos de leitura situados em situações concretas e não artificiais de leitura e escrita, adaptando os objetivos e as estratégias a cada situação específica. Ao propor projetos e criar situações em que os alunos participem de práticas letradas, o professor vai se tornar, de acordo com a autora, um "agente de letramento", deixando de ser um mero 'transmissor de informações".

No final da década de 1990, um grupo de pesquisadores oriundos de países anglófonos reunidos em um encontro realizado em Nova Londres, nos Estados Unidos, propôs o conceito de multiletramento como forma de incluir, aos estudos de letramento, duas questões centrais para a sociedade contemporânea: a multiculturalidade promovida pela globalização e as novas linguagens produzidas e popularizadas com o avanço das tecnologias digitais, as quais extrapolam o sistema da escrita baseada no código alfabético, integrando outros sistemas ('modos', de acordo com a terminologia usada por esse grupo) semióticos, como o som e a imagem. Como resultado desse colóquio, foi proposta, inclusive, uma Pedagogia dos Multiletramentos, com ênfase na multiculturalidade e na multimodalidade (KALANTZIS et al., 2019).

Essa tentativa de ampliar o conceito de letramento para além da escrita alfabética juntamente com a necessidade de ressaltar a especificidade de vários contextos, espaços culturais e gêneros discursivos mais específicos onde ocorrem práticas de letramento levou, nos últimos anos, à proliferação de 'letramentos adjetivados', o que Rojo e Moura (2019, p. 37) caracterizaram como "uma explosão de denominações para além de 'novos' e 'multiletramentos', tais como: letramento visual, letramento televisivo, cineletramento, letramento informacional, letramento digital etc." É dentro desse contexto de novos letramentos adjetivados, portanto, que surgem os conceitos de letramento digital e de letramento literário.

Num sentido amplo, ambos esses conceitos podem ser compreendidos simplesmente como qualquer prática de comunicação situada na qual os sujeitos utilizam ou produzem textos/signos vinculados ao universo digital e/ou ao universo literário. Num viés pedagógico, por sua vez, interessado no papel que as instituições de ensino e seus agentes desempenham para promover tanto letramentos digitais quanto letramentos literários de qualidade, é necessário estabelecer uma linha de contato entre as culturas digital e literária nas quais os estudantes estão hoje inseridos, de um lado, e "ensinar as habilidades e competências necessárias para participar de eventos de letramento relevantes para a inserção e participação social; ensinar como se age nos eventos de instituições cujas práticas de letramento vale a pena conhecer; criar e recriar situações que permitam aos alunos participar efetivamente de práticas letradas" (KLEIMAN, 2005, p. 18), de outro lado. 
Tendo em vista esse panorama, é possível sintetizar, a partir dos seguintes pontos, os principais fundamentos que devem ser levados em conta quando se pretendem promover práticas situadas e significativas de letramento digitalliterário na escola, seja de forma presencial, seja através de ferramentas tecnológicas como as bibliotecas digitais: no que diz respeito à ideia dos letramentos como práticas sociais, as atividades devem tentar romper com a artificialidade das práticas geralmente propostas no ambiente escolar, tornandoas situadas e contextualizadas; para tanto, é necessário reconhecer e/ou fazer uso das práticas letradas que os alunos já possuem previamente em ambientes digitais e em círculos onde são consumidos textos ficcionais e poéticos.

Levando em conta o letramento digital, as atividades devem estimular a colaboratividade entre os alunos - típica das práticas letradas que ocorrem em ambientes digitais -, quebrando o paradigma dos trabalhos individuais que prevalecem na escola, não importando se essa colaboração ocorrerá de forma mediada pela própria plataforma ou presencialmente. Além disso, as atividades devem explorar, na medida do possível, os aspectos multimodais da linguagem que predomina no ambiente digital, disponibilizando livros com graus de interatividade, multi- e hipermidialidade, por exemplo, ou propondo tarefas nas quais os alunos possam produzir textos multimodais.

Por fim, levando em conta o letramento literário, para além do entretenimento, da diversão e das formas interativas de socialização e projeção da imagem individual que marcam muitas atividades literárias na Internet - tais como as fanfics, canais de booktubers, produção de ficção e poesia em plataformas de autopublicação, entre vários outros -, a escola pode propor atividades que auxiliem o estudante a fruir da literatura enquanto arte, percebendo a sutileza e a riqueza na construção da linguagem literária, garantindo, desta forma, "a função essencial de construir e reconstruir a palavra que nos humaniza" (COSSON, 2014, p. 23).

\section{LIVROS DIGITAIS E PLATAFORMAS DE LEITURA}

Uma das primeiras reações do mercado editorial ao cenário das tecnologias digitais foi oferecer, para compra e venda, versões digitalizadas de livros anteriormente impressos, os assim chamados e-books estáticos, que podem ser lidos em um desktop, em um smartphone, em um tablet, mas também nos ereaders (livros eletrônicos) produzidos por empresas como a Amazon - o Kindle , entre outras. No campo da crítica literária dedicada à literatura digital, é comum utilizar o conceito literatura digitalizada para se referir a esse tipo de texto, pois se trata de obras criadas a partir de programas como Pdf ou Epub, entre outros, os quais procuram reproduzir digitalmente o formato do livro impresso, como a capa e as páginas numeradas em sequência linear. Alguns programas, inclusive, permitem criar a ilusão de que o leitor está virando as páginas ao tocar em algum ícone de navegação (geralmente representado com flechas ou setas). No que se refere à experiência estético-literária da leitura de e-books estáticos, não faz muita diferença ler Harry Potter, por exemplo, em um livro impresso ou em um tablet, visto que a narrativa, apesar de transposta para algum suporte digital, continuará mantendo suas características formais e estéticas vinculadas ao suporte impresso. 
Por outro lado, a possibilidade de digitalizar livros impressos e de produzir ebooks estáticos apresenta vantagens inquestionáveis para o leitor, principalmente relacionadas com a facilidade do acesso às obras. Um exemplo é o surgimento de vários projetos de bibliotecas virtuais gratuitas ao redor do mundo, permitindo que qualquer pessoa conectada à rede escolha e acesse livros sem precisar comprá-los. Alguns exemplos de bibliotecas digitais gratuitas são a iniciativa internacional Projeto Gutenberg (http://www.gutenberg.org/) e projetos brasileiros, como o Domínio Público (http://www.dominiopublico.gov.br) e a Biblioteca Virtual da UFSC (http://www.literaturabrasileira.ufsc.br/). No campo da literatura infantojuvenil, pode ser destacado o projeto ICDL - International Children's Digital Library (Biblioteca Digital Internacional para Crianças), disponível em http://en.childrenslibrary.org, o qual contém um amplo acervo de e-books infantis de diferentes autores ao redor do mundo, em vários idiomas.

Nos últimos anos, os projetos que mais têm prosperado são plataformas de livros digitais desenvolvidas com fins comerciais, o que lhes confere um caráter híbrido entre biblioteca e livraria/loja virtual. Alguns desses projetos buscam se alinhar com a estratégia comercial do streaming para venda de conteúdo digital. Como esclarece Burroughs $(2015$, p. 1), o streaming é um processo tecnológico definido como "conteúdo de multimídia sendo continuamente entregue ao usuário", permitindo, às empresas, atingir seus consumidores de forma personalizada, uma vez que estes podem acessar, dentro de um repositório disponibilizado em uma plataforma, aquilo que desejam quando e como decidirem, desde que realizem pagamentos pré-estipulados. Plataformas de filmes e séries como Netflix, de música como Spotify e de livros como Amazon ou Scribd são exemplos desse modo de comercializar diferentes tipos de produtos digitais na Internet.

No caso da literatura para crianças e jovens, existem já algumas plataformas que disponibilizam seus acervos mediante pagamento de mensalidades ou anuidades, geralmente destinadas para escolas, educadores e pais. No âmbito internacional, podem ser destacadas, entre outras, as plataformas norteamericanas Epic! - Unlimited Books for Kids, disponível em https://www.getepic.com/, e a Raz-kids, disponível em https://www.raz-kids.com/ entre outras. No Brasil, esse tipo de plataforma ainda não é tão popular quanto nos EUA, embora já existam alguns projetos nacionais baseados na estratégia do streaming. Como exemplo, pode ser citada a própria plataforma Elefante Letrado, objeto de análise deste artigo.

Esse tipo de plataforma, mesmo que comercializada e não gratuita, possui um elevado potencial pedagógico e pode servir como ótima ferramenta de estímulo à leitura, na medida em que compartilha as principais vantagens atribuídas, por Procopio (2005, p. 28), às bibliotecas digitais, as quais abrangem não apenas a facilidade de acesso às obras, mas também a possibilidade de continuar adicionando títulos a um acervo já existente sem a necessidade de investir em infraestrutura física. Outros recursos, como fornecimento de relatórios detalhados sobre o uso dos livros, pesquisa de palavras em um livro ou em uma coleção inteira de livros, atividades de leitura e interpretação que podem ser postadas em formato de texto (verbal ou multimodal) e/ou vídeo também são muito úteis, sem falar nas inúmeras possibilidades que esse tipo de ambiente propicia para a interação do leitor com o professor e/ou com outros leitores, bem como do professor com os pais e outros sujeitos. 
Por outro lado, também é importante levar em conta algumas limitações e questões a serem pensadas quanto ao emprego desse tipo de ferramenta no trabalho com a leitura de obras literárias em ambiente digital. Primeiramente, assim como no caso de uma biblioteca ou de uma livraria física, é importante verificar a qualidade das obras e dos acervos disponíveis a partir de critérios literários e pedagógicos, pois nem todas as plataformas existentes são desenvolvidas com assessoria de pedagogos ou de profissionais devidamente qualificados na área da literatura. Em segundo lugar, as plataformas e as atividades nelas disponíveis não substituem um mediador e tampouco substituem todos livros impressos, sendo melhor aproveitadas justamente a partir de um bom trabalho baseado em estratégias de mediação, voltados para a leitura e a interpretação das obras; especialmente problemática é a ideia de que atividades baseadas em estratégias de gamificação como a entrega de medalhinhas, de estrelinhas e de outros prêmios aos alunos que atingem certos patamares considerados, segundo os indicadores pré-programados de cada plataforma, como de excelência - seriam bons substitutos para atividades de mediação realizadas a partir de estratégias contextualizadas e criativas de leitura e interpretação. Nesse sentido, é importante ressaltar que dificilmente as atividades postadas e programadas em uma plataforma serão adequadas para todos os contextos, e isso é especialmente válido no caso das avaliações, pois relatórios produzidos automaticamente com base em indicadores pré-estabelecidos de forma homogênea e estática podem ser úteis em alguns casos, mas certamente não serão adequados em outros. Por último, também é importante mencionar que, no campo da literatura infantojuvenil, alguns pesquisadores consideram controvertida a adaptação de livros impressos ao formato de e-books estáticos principalmente devido à perda quanto à experiência/sensação estética baseada no tamanho e na textura do papel, que ocorre quando o autor do livro impresso havia feito um uso artístico desses elementos (YOKOTA; TEALE, 2017).

\section{O ELEFANTE LETRADO}

Nesta seção, o objetivo é avaliar a plataforma de leitura Elefante Letrado à luz dos principais pontos elencados como fundamentais para a promoção de um letramento digital e literário de qualidade na escola, a saber, a) a seleção de um acervo de qualidade; b) propostas de atividades situadas e contextualizadas em relação às práticas letradas que os alunos já possuem previamente em ambientes digitais e em círculos onde são consumidos textos ficcionais e poéticos; c) estímulo à colaboratividade entre os próprios alunos, bem como interação com outros sujeitos; d) exploração dos aspectos multimodais da linguagem tanto no que diz respeito aos livros quanto no que diz respeito às atividades propostas; e) atividades que permitam reconhecer e fruir a riqueza da linguagem literária e artística.

Antes de refletirmos sobre os pontos elencados acima, é necessário destacar alguns aspectos preliminares sobre a navegação na plataforma, baseados na experiência de acompanhamento do aluno MR. Até o momento, MR demonstrou pouco interesse em explorar esse novo ambiente; por parte da escola, por sua vez, a indicação de tarefas e de leituras a serem feitas tem sido realizada exclusivamente na própria plataforma, o que significa que só serão descobertas quando (e se) o aluno realizar o acesso. Outra questão a ser destacada é que o 
acesso às obras da plataforma não é livre, pois o aluno consegue acessar apenas aquelas destinadas ao seu próprio ano escolar, no caso, o quinto ano. Além disso, o aluno fica impossibilitado de explorar mesmo as obras de seu próprio ano escolar caso não termine alguma tarefa proposta pela professora na plataforma, sendo que o usuário não é informado de que ocorre um bloqueio aos demais livros enquanto houver uma tarefa por finalizar. Somente após contato presencial com a professora de língua portuguesa, com a coordenadora pedagógica do colégio e com a equipe de suporte técnico da Plataforma, foi possível que o aluno/leitor MR navegasse por todo o ambiente, tendo acesso também às obras literárias destinadas aos primeiros, segundos, terceiros, quartos e quintos anos. Passada essa etapa de reconhecimento do processo de navegação, observamos que a limitação do acervo ao respectivo ano de cada aluno desmotivou MR a continuar explorando aquele ambiente, pois o aluno achou os livros muito infantis: "Coisa de criança", afirmou com frequência.

O principal mérito da plataforma é a extensão e a qualidade do acervo bem como a relativa facilidade de acesso aos livros. A Plataforma possui mais de 560 livros em português, 174 autores e 22 gêneros textuais e mais de 400 livros em inglês (https://www.elefanteletrado.com.br/acervo/). Segundo informações fornecidas na própria plataforma, a seleção do acervo literário é realizada por uma curadoria, formada por pedagogos e educadores, levando em consideração a faixa etária das crianças. O sistema está organizado com base em cinco níveis de proficiência em compreensão leitora, que possuem subníveis nomeados por letras de $A$ até $Z$, o que garante a sua pertinência aos anos iniciais do ensino fundamental. Dentre os principais autores, destacam-se vários consagrados da literatura infantil brasileira, tais como Monteiro Lobato, Ziraldo, André Neves, Fernanda Lopes de Almeida, Sérgio Caparelli, entre outros. Destaca-se também como positivo o fato de estarem representados diferentes gêneros literários e não-literários: poemas, documentários, narrativas, trava-línguas, biografias etc. Da mesma forma, os livros permitem abordar temáticas diversas e polêmicas, como a diversidade, a morte, as desigualdades sociais, a sustentabilidade. Outro aspecto que merece destaque positivo é a diversidade de editoras, tais como Editora Projeto; Editora Callis, Editora Globo, Artes e Ofícios, Abacatte, entre outras.

No que diz respeito ao modo como a plataforma disponibiliza os livros, visto se tratar de livros eletrônicos estáticos, podem ser acessados no computador, tablet ou smartphone, sendo que o design da plataforma emula uma estante de livros físicos, conforme a figura abaixo:

Figura 1: Biblioteca da Plataforma Digital de Leitura Elefante Letrado

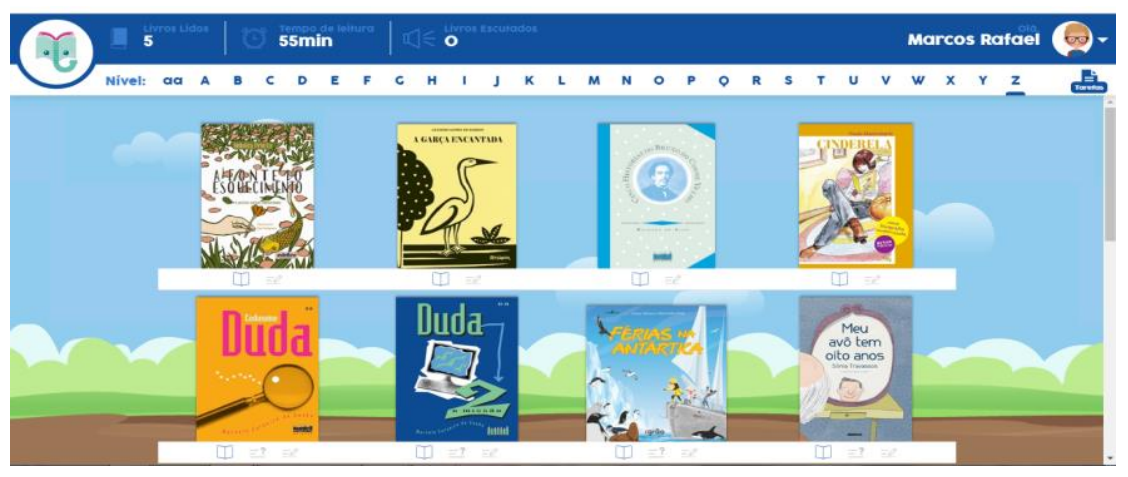

Fonte: Login MR 
Além disso, a plataforma também secciona o acesso de acordo com a idade ou o avanço escolar. Nas turmas de primeiro ano, são disponibilizados apenas livros de palavra/objeto, abecedários, bem como livros de frases curtas, em versos e com pequenas narrativas, destinados a leitores iniciantes. É interessante pontuar que os gêneros parlendas, cantigas, trava-línguas, adivinhas são bastante presentes nos três primeiros anos, provavelmente devido ao seu caráter lúdico e à possibilidade de um trabalho relacionado ao desenvolvimento da consciência fonológica no processo de alfabetização (MORAIS, 2012; 2019). Já para os quartos e quintos anos, os livros disponibilizados apresentam narrativas maiores, mais complexas, e alguns deles possuem menos imagens, o que permite supor que são destinados a um leitor considerado fluente. Observa-se uma intensificação em gêneros como prosa, narrativas poéticas, fábulas, relatos de viagem, entre outros.

Esse modo hierarquizado de disponibilizar os livros, baseado em 'níveis de leitura', está de acordo com uma visão cognitivista-afetiva do desenvolvimento humano, em que as condições etárias definem tanto a estrutura do texto quanto o tratamento temático que lhe é dispensado; a ideia é que, para cada faixa etária, cabem propostas de letramento literário ligadas às supostas expectativas e necessidades dos leitores em seu estágio específico de desenvolvimento. Essa perspectiva sobre letramento literário também subsidia, com frequência, propostas pedagogizantes de trabalho com a literatura, as quais ressaltam aspectos gramaticais e de compreensão literal em detrimento da leitura livre e voltada apenas para a fruição do próprio texto. Assim sendo, esse tipo de restrição vai de encontro à liberdade e à criatividade que marcam a linguagem artística e literária, de um lado, e também à liberdade que impera nos ambientes digitais em que ocorrem práticas de leitura e discussão de textos literários, de outro.

De forma geral, o design de toda a plataforma segue um padrão bastante engessado e, dessa forma, revela-se alinhado com uma perspectiva pedagógica tradicional - que é hierarquizante e reguladora - e, portanto, distante da visão socioantropológica propagada pelos estudos sobre letramentos. Em outros termos, ao invés de colaboratividade e de contextualização, predomina, nas atividades propostas naquele espaço, a valorização do desempenho individual e do controle exercido sobre a leitura, que ocorre tanto por parte do professor como por parte de alguns artifícios automáticos da própria plataforma.

Esse aspecto se torna evidente já no processo de seleção das obras a serem lidas. Embora a seleção do livro a ser lido possa ser realizada tanto pelo aluno quanto pelo professor, caso a leitura seja proposta pelo professor, o aluno só conseguirá navegar nos demais espaços da plataforma após o término da tarefa designada. (FIGURA 2).

Figura 2: Tarefa

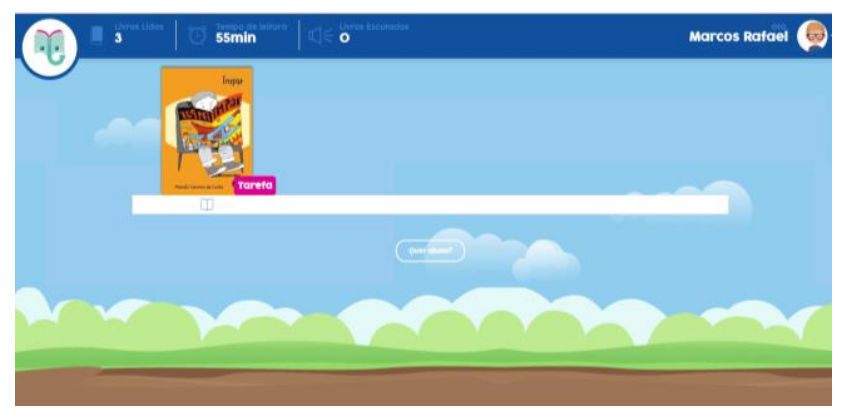

Fonte: Login MR 
Além disso, há um algoritmo que "mede" o tempo de leitura. Assim sendo, se o aluno desejar fazer uma leitura mais dinâmica do texto, não conseguirá finalizar a leitura e liberar o sistema para a escolha de outros livros, pois o algoritmo de "regulação do tempo de leitura" acusa como se o texto não tivesse sido lido. Esse fator é ressaltado como algo produtivo por parte dos gerenciadores da Plataforma, pois, para Mônica, por exemplo, a escola em geral desconhece que existe um tempo mínimo necessário para a leitura que deve ser respeitado, sendo, em sua opinião, a fluência (velocidade) da leitura um dos maiores indicadores da compreensão leitora. Ainda segundo Mônica, "acompanhar a evolução do ritmo de leitura traz fortes indícios de que o aluno também está desenvolvendo a compreensão leitora". (http://blog.elefanteletrado.com.br/inscer-elefanteletrado-aprendizado-da-leitura/). O aluno cuja interação foi analisada nesta pesquisa, "MR", por exemplo, realizou a leitura dos livros designados juntamente com sua mãe e, provavelmente por essa razão, o ritmo da leitura foi um pouco mais fluente, o que fez com que o algoritmo do sistema considerasse que a leitura não fora realizada de forma satisfatória. Esse tipo de enrijecimento não leva em conta a possibilidade de múltiplos contextos de leitura tampouco a existência de perfis diferenciados de leitor; portanto, não se alinha com a visão dos letramentos sociais. (FIGURA 3).

Figura 3: Tarefa

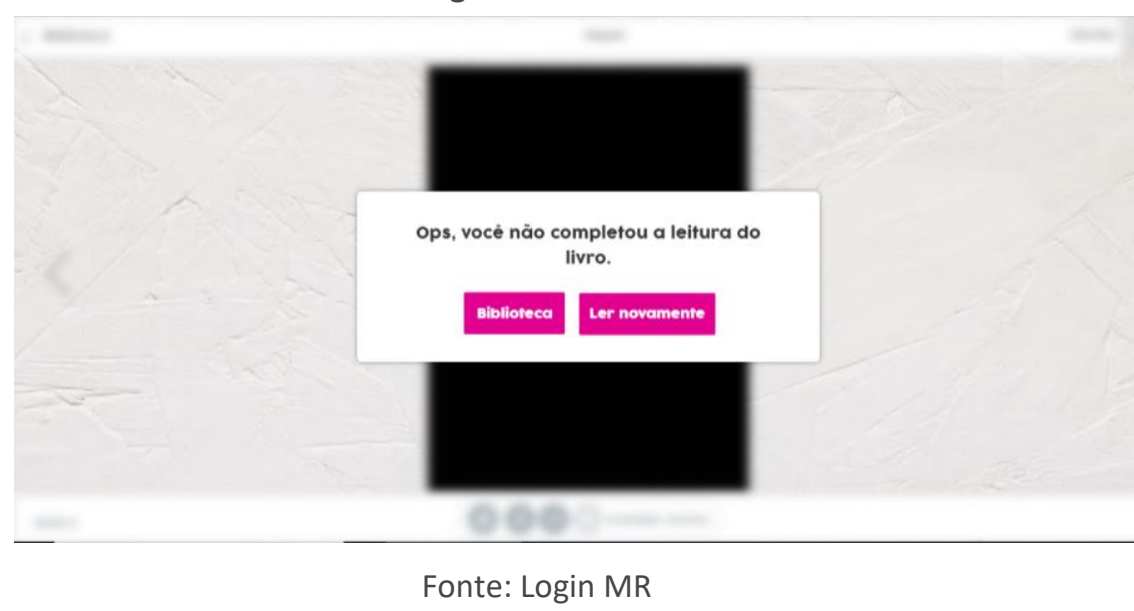

Outro mecanismo de controle a ser destacado quanto às atividades de compreensão leitora é o fato de gerarem relatórios de desempenho sobre as obras lidas. Os dados do relatório podem ser gerados por turma ou por aluno. De acordo com informações do site, nas palavras de Mônica Timm de Carvalho, CEO do Elefante Letrado, "por meio de perguntas sobre as obras lidas pelos estudantes, a plataforma fornece indicadores sobre o grau de apropriação dos alunos sobre os textos de diferentes gêneros." Também é possível gerar índices sobre o número de obras lidas e o tempo de leitura. Essa ênfase em relatórios revela novamente um alinhamento dessa plataforma com uma visão mais cognitivista e menos socioantropológica e mesmo literária, enfatizando, por essa razão, a "performance" e o "controle" em detrimento do deleite e do prazer. Os alunos são considerados bons ou ótimos caso se deixem envolver por um certo ímpeto competitivo, promovido naquele ambiente, para mostrarem que seu desempenho é o melhor. Como exemplo, pode ser citado o caso de um aluno mencionado também no site do Elefante Letrado: "Carlos foi o aluno do 2o ano B que mais leu livros nos dois primeiros trimestres, 72 no total. Por isso, além de receber a dupla 
certificação do Elefante Letrado, recebeu a medalha pelo seu desempenho". Segundo informações retiradas do blog do Elefante Letrado, os alunos são avaliados através de atividades pedagógicas atreladas a um descritor, previsto para a Provinha Brasil e Prova Brasil do Saeb/ MEC/Brasil no eixo da leitura. (http://blog.elefanteletrado.com.br/elefante-letrado/).

No que diz respeito aos aspectos mais especificamente ligados às estratégias voltadas para o letramento digital, há duas questões a serem destacadas: primeiro, a plataforma faz uso tímido de estratégias que proporcionem a leitura interativa, colaborativa, multimídia ou hipermídia; segundo, a plataforma estabelece um diálogo com a cultura digital principalmente através de estratégias de gamificação da leitura. Visto que os livros disponibilizados são predominantemente estáticos, a leitura do livro eletrônico, naquele ambiente, acaba sendo muito semelhante à leitura de um livro impresso, não sendo explorados, por exemplo, recursos de interatividade e multimidialidade típicos dos livros digitais não-estáticos. (FIGURAS $4,5$ e 6$)$.

Figura 4: Tarefa proposta: Leitura do livro Ímpar, de Marcelo C. da Cunha - Abertura

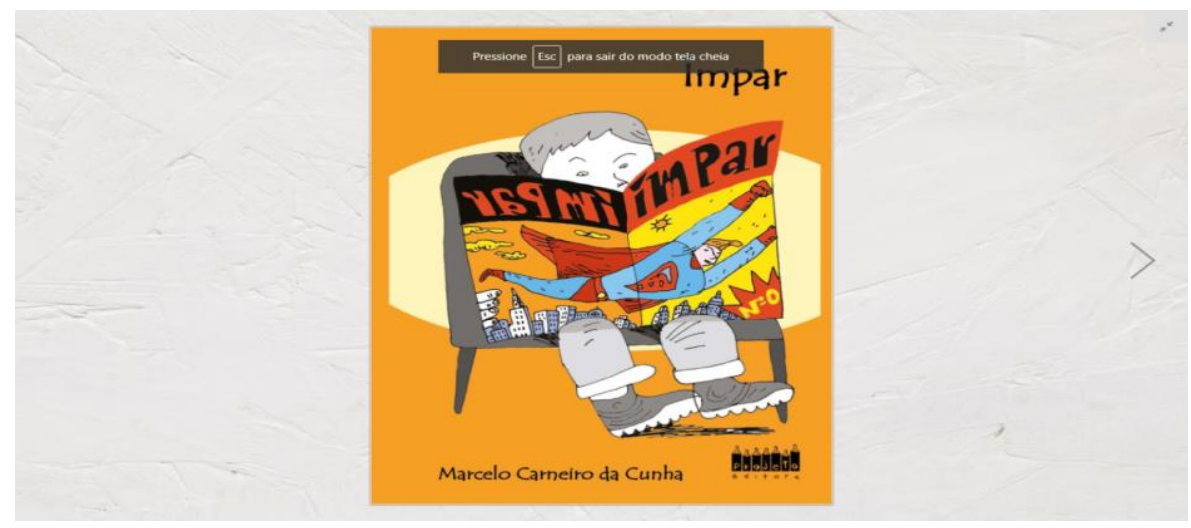

Fonte: Login MR

Figura 5: Tarefa proposta: Leitura do livro Ímpar, de Marcelo C. da Cunha - Texto

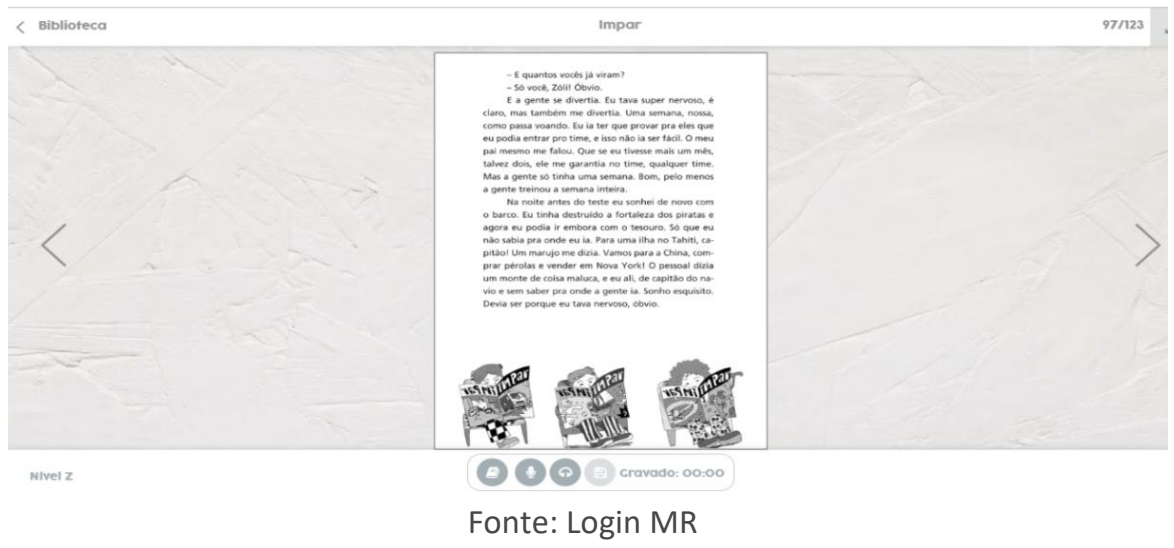


Figura 6: Página de entrada para a atividade de Compreensão Leitora

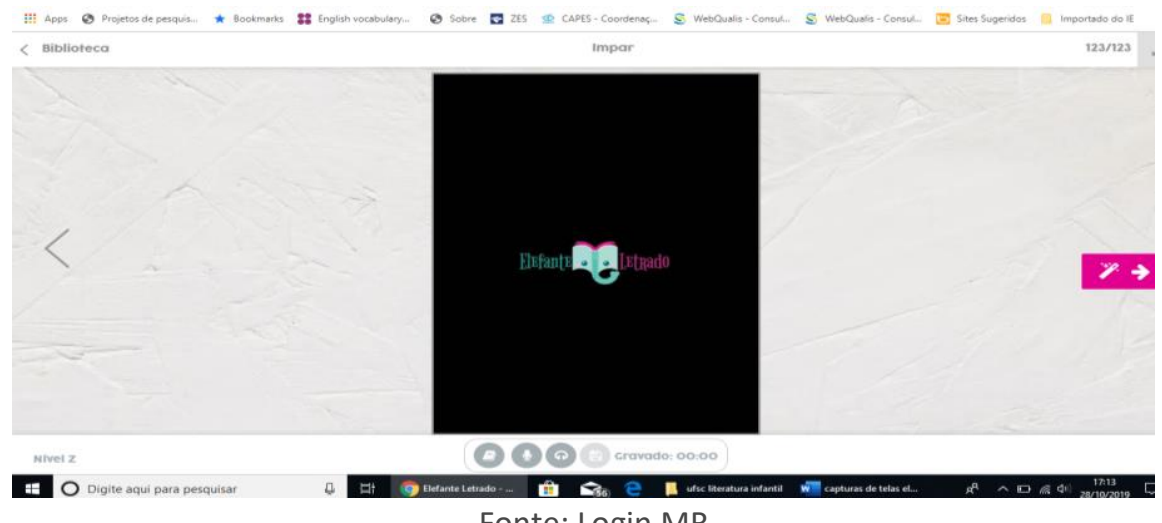

Também é importante salientar a presença de elementos de gamificação na plataforma. A gamificação pode ser definida, em termos bastante sintéticos, como a apropriação de elementos estruturais e discursivos dos jogos eletrônicos a outros contextos de interação social. No campo da educação, Karl Kapp (2012) acredita que há dois principais tipos de gamificação: a gamificação estrutural e a gamificação de conteúdo. A primeira se caracteriza como a aplicação de elementos de jogos eletrônicos para estimular o aluno a aprender algum conteúdo sem alteração ou alterações no próprio conteúdo. Nesse caso, o conteúdo não se torna semelhante ao jogo, mas a estrutura em torno do conteúdo sim. A gamificação de conteúdo, por sua vez, se caracteriza como a aplicação de elementos típicos de jogos para alterar o próprio conteúdo, tornando-o mais semelhante a um jogo. No caso dos livros eletrônicos interativos, por exemplo, quando os recursos de interatividade são utilizados como elementos narrativos, acabam transformando a narrativa em um híbrido entre jogo e história. Na plataforma digital Elefante Letrado, observamos alguns elementos que a aproximam de uma gamificação estrutural, podendo ser destacados: os certificados e premiações/recompensas, os jogos e questionários (vistos como um desafio), o display da performance (resultados alcançados) da leitura e o respectivo estímulo à competitividade.

Salientaremos aqui os jogos e questionários vistos como desafios, uma vez que estes foram mobilizadores para que "MR" desejasse fazer as tarefas. Ele expressou estar consciente de que, ao final, haveria uma pontuação/recompensa para seu esforço em responder às questões. $O$ grande perigo desse tipo de estratégia é que pode levar o aluno a realizar a leitura unicamente pelo prazer da competição - pois o que passa a contar para os alunos é a pontuação e não necessariamente o deleite da leitura e da reflexão sobre a obra (FIGURA 7). Vale destacar, também, que as tarefas destinadas ao quinto ano eram geralmente de múltipla escolha e tinham enunciados muito repetitivos, além de demandarem respostas que poderiam ser fornecidas apenas como mera reprodução de alguma informação explícita no próprio texto, tais como, por exemplo: Marque a frase que mostra uma opinião do personagem; Assinale o lugar onde aconteceu a história. Contudo, segundo o blog da Plataforma, há também jogos de perguntas e jogos de memória, entre outros. Somente ao completar $75 \%$ dos livros e das atividades disponíveis, o aluno consegue acessar os títulos do nível seguinte. 
Figura 7: Amostra da pontuação do desafio realizado

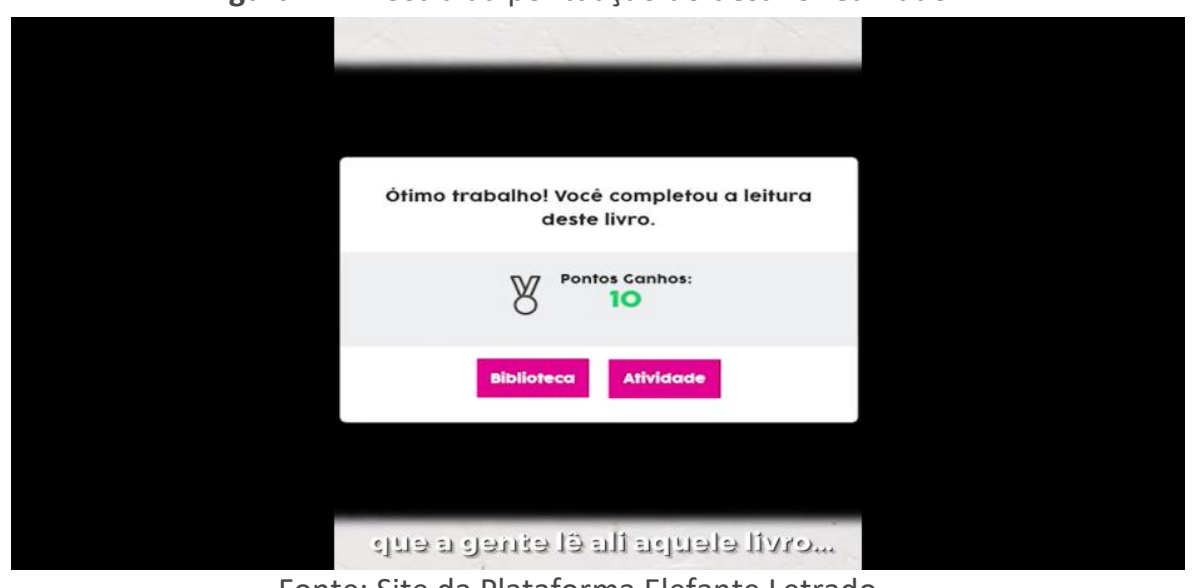

Fonte: Site da Plataforma Elefante Letrado

É interessante destacar também que a Plataforma, segundo Mônica Tim, "permite que os pontos adquiridos possam ser trocados por alguns minutos de bate-papo entre os alunos". Mas, ainda segundo Mônica, essa é uma ferramenta opcional, e "muitas escolas preferem não utilizá-la, já que precisam gerenciar possíveis conflitos que fazem parte do uso de qualquer rede social". (http://blog.elefanteletrado.com.br/elefante-letrado/). A pouca ênfase em recursos de interatividade entre usuários empobrece a capacidade da plataforma para promover um letramento digital de qualidade, uma vez que limita a possibilidade de realização de projetos coletivos e também de criar situações e contextos em que os leitores poderiam trocar ideias sobre as obras lidas.

\section{PALAVRAS FINAIS}

No que tange aos aspectos do letramento literário e digital, como já se afirmou anteriormente, o principal mérito da plataforma é facilitar e estimular o acesso a obras de qualidade através de livros eletrônicos, visto que o acervo contém livros de autores consagrados e de elevada qualidade estético-literária. Por outro lado, a plataforma enfatiza sobremaneira uma visão regulatória, individualizante e cognitivista da leitura literária, em detrimento de aspectos que poderiam explorar o próprio prazer da leitura, a colaboratividade entre os usuários daquele espaço e, inclusive, a possibilidade de realizar projetos que poderiam transitar, como transmídia, para fora da plataforma, em outros espaços digitais.

A análise do material a que tivemos acesso na plataforma levou à conclusão de que a maior parte das atividades complementares à leitura está alinhada com uma visão tradicional de letramento. Ler apenas para apropriar-se da especificidade do gênero ou para reconhecer e localizar informações explícitas no texto vincula-se a um letramento escolar muito característico de propostas literárias pedagógicas tradicionais, o modelo autônomo de letramento, segundo Street (2013). Tal concepção baseia-se na suposição de que o letramento por si só - autonomamente - terá efeitos sobre outras práticas sociais e cognitivas. Assim sendo, introduzir o letramento para as crianças na escola teria o efeito de intensificar suas habilidades cognitivas. 
Ao incluir elementos de gamificação, por sua vez, os quais estimulam a competitividade e a performance, a plataforma também acaba se distanciando de uma visão da literatura como instrumento para a humanização e fonte de prazer artístico. A leitura como deleite, segundo Geraldi (1997), deveria estimular o aluno a "perceber a beleza do texto, sem que ele leve consigo questões previamente enunciadas, [...] devendo ter como único propósito os fins estéticos, poder sentilo por completo, sem é claro perder de vista o enredo contido nele". Finalizando, importa apontar também que a plataforma Leitura Elefante Letrado, embora queira se situar num campo diferenciado sobre a leitura e a compreensão leitora, acaba por repetir predominantemente uma visão tradicional de letramento escolar, a qual enfoca a compreensão individual da leitura pelo aluno, resvalando para uma cultura escolar já cristalizada que prioriza a avaliação da leitura em detrimento da liberdade, da criatividade e do simples prazer de fruir um texto produzido artisticamente. 


\title{
Literary and digital literacies: the digital libraries for children and the case of Elefante Letrado
}

\begin{abstract}
In this paper we present the result of an analysis of the Brazilian digital library Elefante letrado (http://www.elefanteletrado.com.br/) in the light of the field of study dedicated to critical digital literacies. Some of the main theoretical concepts we draw on are 'digital literacy' and 'literary literacy', taking the Elefante letrado as a case study. The main purpose of the analyses is to point out the perspectives regarding literary digital literacy the Elefante letrado is in tune with. In order to achieve this goal, we draw on authors and researchers from the field of literacy studies such as Brian Street, Roxane Rojo, Rildo Cosson, Angela Kleiman, Eduardo Moura, among others. Furthermore, our discussion on digital books and digital libraries is based on researchers such as Procopio, Teale e Yokota, among others
\end{abstract}

KEYWORDS: Digital libraries. Literary literacy. Digital literacy. Digital literature for children and young adults. 


\section{REFERÊNCIAS}

BURROUGHS, B. E. Streaming media: audience and industry shifts in a networked society. Iowa: University of Iowa, 2015. Tese de Doutorado. Disponível em: http://ir.uiowa.edu/etd/1833 Acesso em: 24 out. 2018

CHAMBERS, Aidam. Dime. Espacios para la lectura. Mexico: Fondo de Cultura Economica, 2007.

COSSON, Rildo. Letramento literário: teoria e prática. São Paulo: Contexto, 2014.

GERALDI, João Wanderley. Portos de passagem. 4. ed. São Paulo: Martins Fontes, 1997.

KALANTZIS, Mary; COPE, Bill; CHAN, Eveline; DALLEY-TRIM, Leanne. Literacies. 2. ed. United Kingdom: University Printing House, 2019.

KAPP, K. M. The Gamification of Learning and Instruction: Case-Based Methods and Strategies for Training and Education. New York: Pfieffer, 2012.

KLEIMAN, Angela B. Preciso "ensinar" o letramento? Não basta ensinar a ler e a escrever? Campinas: Cefiel/IEL/Unicamp, 2005.

MORAIS, Artur Gomes. Sistema de escrita alfabética. São Paulo: Melhoramentos, 2012.

Consciência fonológica na educação infantil e no ciclo da alfabetização. Belo Horizonte: Autêntica, 2019.

PROCÓPIO, Ednei. Construindo uma Biblioteca Digital. São Paulo: EI Edições Inteligentes, 2004.

ROJO, Roxane. O letramento escolar e os textos da divulgação científica A apropriação dos gêneros de discurso na escola. Linguagem em (Dis)curso - LemD, v. 8, n. 3, 2008. 
ROJO, Roxane; MOURA, Eduardo. Letramentos, mídias, linguagens. São Paulo: Parábola, 2019.

STREET, Brian V. Letramentos sociais: abordagens críticas do letramento no desenvolvimento, na etnografia e na educação. São Paulo: Parábola Editorial, 2014.

Políticas e práticas de letramento na Inglaterra: uma perspectiva de letramentos sociais como base para uma comparação com o Brasil. Caderno do CEDES. Centro de Estudos Educação e Sociedade. v. 33. Jan./abr. 2013.

YOKOTA, Junko; TEALE William H. Livros de imagem e o universo digital: educadores realizando escolhas conscientes. Fronteiraz, n. 18 (2017), disponível em: https://revistas.pucsp.br/index.php/fronteiraz/article/view/32903. Acesso em: 24 out. 2018.

Recebido: 11 fev. 2020

Aprovado: 28 mar. 2020

DOI: $10.3895 /$ rl.v22n36.11757

Como citar: KIRCHOF, Edgar Roberto; MELLO, Darlize. Letramento literário e digital: as bibliotecas digitais para crianças e o caso do Elefante Letrado. R. Letras, Curitiba, v. 22, n. 36 p. 36-52, mar. 2020. Disponível em: <https://periodicos.utfpr.edu.br/rl>. Acesso em: XXX.

Direito autoral: Este artigo está licenciado sob os termos da Licença Creative Commons-Atribuição 4.0 Internacional. 